\title{
Research on Project-based College English Learning
}

\author{
Shanxiu He \\ School of Foreign Languages, East China Jiaotong University, Nanchang, China \\ 710913621@qq.com
}

Keywords: PBL; Learning mode; College English

\begin{abstract}
Project-based learning is a widely used learning mode in the United States and European countries currently. It is built on Constructivism Learning Theory. This paper will introduce certain main components of the study, such as four major factors, research process, the roles of teachers and students. This peculiar learning mode has great referential significance to the current college English learning in China.
\end{abstract}

\section{Introduction}

Project-based language learning emphasizes the division of labor between language learners, requiring students to take the initiative to explore the answers to questions in real situations, focusing on the ability of students to collect, process information, solve problems, communicate and collaborate. Meanwhile, project-based language learning is very popular among foreign countries, it has also aroused the concern of the domestic education sector in recent years. The PBL model was originally developed from the American School of Neurology Professor Howard Barrows' problem-centered approach, which was originally used in the field of Western medicine teaching because of its direct application of knowledge and the cultivation of future vocational skills. In the three decades, the teaching model has welcomed by the world, especially Europe and the United States. To be more specifically, it is widely used in the field of medicine, biology, psychology, economics, management and other fields of teaching, which made a significant teaching effect. Most of the researches on PBL teaching in our country are also concentrated on the field of medicine, and their writings and papers are quite abundant. In China's college English teaching, there are few PBL learning models based on the project in Chinese college English teaching. The author takes the theoretical basis of this study, and takes its implementation as the practice basis, and finally puts forward the research and reflection on the implementation of PBL in college English teaching and the practical application effect.

\section{Four Components of Project-Based Language Learning}

Project-based learning is mainly discussed from four aspects: research content, research process, scenario setting and research achievement. The content of the research is the reproduction of the complex and interdisciplinary knowledge in the real situation. The content must be complete, not the broken knowledge. The content of the research should be complete and systematic. It should meet the characteristics of the individual with interest and so on. And students need to have the ability to conduct creative research in a certain degree and draw the corresponding results. The research process refers to a series of research actions taken by students using certain means or tools, research methods, and trying to solve the problems they face. In project-based learning activities, the projects studied need to be challenging. In the course of the study, students will encounter some difficulties which help them to promote students to mastery of the real life with complex concepts and skills including using these skills to complete a similar task in different scenarios, the implementation of professional duties, the formation of a certain work performance, and to improve their skills through a series of activities. These activities are constructive, because the project-based learning allows students to build and generate their own knowledge, so they are easy to remember and migrate knowledge. In project-based learning, activities provide students with a learning experience that students can build their own knowledge. Students first determine the problem, and then seek a solution to the problem, and analyzing information. Finally they 
learned to integrate the new information obtained before the knowledge linked to the final formation of works. Students gained knowledge of the construction activities through this process, and adapt to different ways to learn with personalized project-based learning, conversely it also give students a variety of ways to participate in; Students can also adapt to different learning styles, such as individual learning or group learning.

Scenario settings are intended to support students in initiating an initial environment based on project learning, which can be either a real-life environment or a virtual environment formed by multimedia technology. The scenario facilitates student-based, project-based learning to provide students with a real learning experience because they are carried out in a yearly event, not just in a monotonous classroom environment. Some projects even can be carried out in some community environments. In this scenario, learning and work require interdependence and cooperation. This environment allows students to reduce interpersonal conflicts and help them solve interpersonal conflicts. It is conducive for students to use and master the technical tools without pressure. It provide an ideal environment for students to learn and use a variety of technologies to develop students' abilities and prepare them for the community at the same time.

The research results showed that students have promote their knowledge and problem solving strategies, such as group learning skills, life skills, self-management skills, etc. The purpose of PBL is to provide students with the opportunity to develop their professional skills and training professional research strategies, and to promote students' ability to improve their self-learning and develop their life-long learning. These results can be revealed mainly through the student's final work show. The teacher's duty is to record the performance of the student in the activity and to build a platform to show the student's results and to show the student's work before the end of the event. The form of research results is diversified. Students can form different forms of final products according to the activities of the project. They can be research reports or investigation reports. They can also be songs and dances, sketches, paintings and so on. Various types of works are produced according to the students' own wishes. In the project learning, even the same type of work, its content is varied.

\section{The Main Process of Project-Based Language Learning}

This study emphasizes student-centered, the group's cooperative learning, and asking students to explore the realities of real life. First of all, we need to select the appropriate project under the guidance of the teacher based on student interest, and take into account the daily experience of students, as well as personal expertise to select the project theme, so that they can put forward some related issues. Secondly, in addition to the basic ability to read and to write, the project should be able to integrate a number of disciplines to develop interdisciplinary research ability, to a certain extent, and expand the students' knowledge. At the same time, it is possible to take into account the existing knowledge and ability of the students, and whether it is possible to solve the various problems that arise in the project through efforts to achieve the goal of project learning. In the process of selecting a project theme, the teacher can only act as the mentor, that is, the teacher can not impose a project on the student. Teacher's role is to evaluate the theme student selected, for instance, does the subject have research value? And whether the student has the ability to study the project, and if necessary, adjust the student's selected items, or suggest that the project be re-selected if necessary.

After the selection of the project, you need to do research plan. Taking into account the details of the project study, e.g., the detailed arrangements for the study time and the schedule of activities; activity design refers to the PBL. The activities are involved in the planning to help students master the progress of regulatory activities, but also conducive for the participants to guide, adjust and evaluate the entire project learning. The process phase of the study is the core of the project learning, and most of the student's knowledge and skills are done in the process. It is made up of a thorough study by the study group, which usually includes traveling to certain area, conducting research on the necessary places, objects or events, or interviewing certain people. In the course of the investigation and study, the students carry out the necessary records on the contents of the activities and their own views or feelings on the activities, put forward the hypothesis to solve the problem, and then use the factory research 
methods and technical tools to collect information, followed by the information processing. The last step is to verify or overturn the assumptions of the beginning, and finally come to the solution to the problem or the results.

Production stage: students' works. Project-based learning is different from the general activities of the typical teaching. It is mainly reflected in the students' works and achievements. In the process of research activities, students use the knowledge and skills acquired in the learning process to complete the production of the work. During the stage of the work, the learning team describes the projects they are studying and shows their research results which reflect their knowledge learned in the project.

One of the important differences between project-based learning and traditional teaching lies in the learning evaluation model - the quantitative and qualitative evaluation, the formative evaluation, the summative evaluation, the evaluation of the individual and the evaluation of the group - which are really combined in the PBL. The contents of the evaluation are: the choice of the subject, the performance of the student in the group study (the cooperation between the members of the group during the event), the plan, the schedule, the result expression and the result display. The evaluation of the results emphasizes how much knowledge and skills the students get. The evaluation process emphasizes the experimental record, a variety of raw data, activity records, questionnaires, interviews, learning experience. The evaluation can be done by an expert, a scholar, and a teacher, or a companion or a learner himself. Teachers can observe the skills and knowledge that students use in the course of project learning. Students can reflect their own work as well as the work of their peers, the team's work, how they feel about the work procedure, and what knowledge and skills they have gained. Other components, for example, reflecting the work, rechecking the process, and making clear the focus and weaknesses in the knowledge area, are part of the learning process.

\section{The Role of Teachers and Students in the Project}

\section{The Role of the Teacher}

The role of teachers in PBL is different from that of tradition, but teachers still have control over the whole learning activities to ensure the smooth progress of learning activities. Of course, the control of learning activities can also be governed by rules and so on, but can not deny the supervision of teachers. Therefore, teachers need to have some strategies to adapt to the new learning model. Teachers have to meet the challenges in the PBL. The role of teachers have been dramatically changed, and some PBL learning projects are open, PBL may involve a wide range of content, so teachers must face some new challenges, such as searching for information Technical mastery, regulation etc.. In the PBL, the teacher must first understand the theme of the project, give guidance on the final product, etc., which need teachers master the relevant knowledge and resources in advance. This is not just a simple question of increasing the workload of teachers, but more importantly, the demand for teachers is improved. Therefore, the focus of the teacher's work has shifted, no longer just to impart knowledge.

\section{The Role of Students}

The role of students is the protagonist of learning activities, they are no longer only in a closed classroom environment with passive acceptance of knowledge. They can choose their own project which can be done by a single or in the form of a group of cooperation. They have to take the initiative to complete the project and form the final product, and show the project as testament of their achievement. Self-evaluation and teacher's evaluation help them to promote learning and so on. In the process of project-based teaching and learning, students are always in the main position, they can do exercises, learn by themselves, and ultimately master the knowledge and principles with the help of teacher. At the same time, the team should have a reasonable arrangement according to the characteristics of the students. Different student corporate together to complete the same project product. Most of the projects need to be completed, but the personality traits of the students are still important. The personality of the students is an important basis for teachers to group or classify the students, and students also choose the combination of members based on their own interests and the characteristics of individuals. Therefore, the analysis of the personality characteristics of students is still 
an indispensable step in the new learning model, their activities are based on the project's final product as the goal, that is, the main activities of the exploration activities are goal-centered.

\section{Recommendations and Future Prospects}

Project-based learning acts as a new type of teaching model in the actual teaching process. There are some urgent contradictions to be resolved, hoping to be able to gradually improve the study of PBL. It is a complete production of the work of the model. The production cycle is relatively long, more time needs to be poured into the process, because the teacher is difficult to effectively grasp the progress of teaching activities in the real context. There are also some difficulties in the management of project-based learning outcomes, and there is currently no specific and effective standard to measure this process. For these problems, you can improve from the following aspects: you need to set a proper project theme, and ensure that the theme can be competed in the current semester. In the process of project-based learning, special emphasis is placed on the spirit of cooperation between the players and the establishment of an effective leadership group, which facilitates coordination with various resources.

\section{Acknowledgements}

This work was supported by Jiangxi Social Science Project for 2015 (15WX202), Jiangxi Teaching Reform of Higher Education Project for 2013(JXJG-13-5-14).

\section{References}

[1]Brindley, G. (1994). Task-centered language assessment in language learning. The promise and the challenge. In: N. Bird, P. Falvey, A. Tsui, D. Allison, \& A. McNeill (Eds.), Language and learning: Papers presented at the Annual International Language in Education Conference, Hong Kong (pp. 73-94). Hong Kong: Hong Kong Education Department.

[2]Brown, J.D., Hudson, T., Norris, J.M., \& Bonk, W. (2002) An investigation of second language task-based performance assessments. Technical Report \#24. Honolulu, HI: University of Hawai'i, Second Language Teaching and Curriculum Center.

[3]Carless, D. (2004). Issues in teachers' reinterpretation of a task-based innovation in primary schools. TESOL Quarterly, 38, 639-662.

[4]Collentine, K. (2009). Learner use of holistic language units in multimodal task-based synchronous computer-mediated communication. Language Learning \& Technology, 13(2), 68-87.

[5]Ellis, R. (2001). Introduction: Investigating form-focused instruction. Language Learning, 51, 1-46.

[6]Fuente, M. J. (2006). Classroom L2 vocabulary acquisition: Investigating the role of pedagogical tasks and form focused instruction. Language Teaching Research, 10, 263-295.

[7]Long, M.H. (2015). Task-based needs and means analysis. In: M.H. Long (Ed.), Second language acquisition and task-based language teaching. Oxford: Wiley-Blackwell.

[8]Swain, M., \& Lapkin, S. (1995). Problems in output and the cognitive processes they generate: A step towards second language learning. Applied Linguistics, 16, 371-391.

[9]Willis, J. (1996). A framework for task-based learning. Harlow, UK: Longman. 